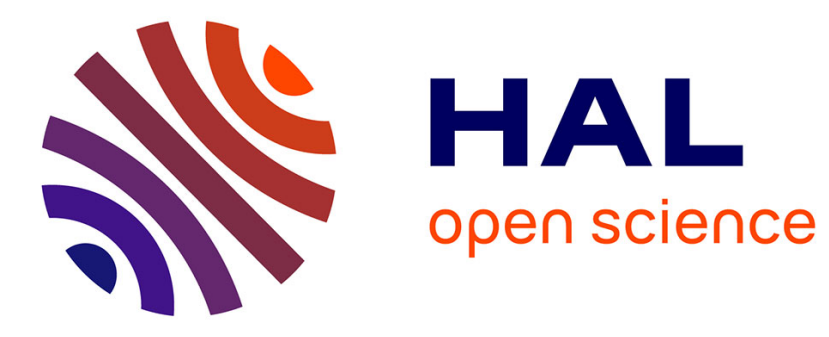

\title{
Phase transformation of mixed Cr1-xAlxN nitride precipitates in ferrite
}

Arno Rainer Clauss, Ewald Bischoff, Ralf Schacherl, Eric Jan Mittemeijer

\section{To cite this version:}

Arno Rainer Clauss, Ewald Bischoff, Ralf Schacherl, Eric Jan Mittemeijer. Phase transformation of mixed Cr1-xAlxN nitride precipitates in ferrite. Philosophical Magazine, 2009, 89 (06), pp.565-582. 10.1080/14786430802709105 . hal-00514011

\section{HAL Id: hal-00514011 \\ https://hal.science/hal-00514011}

Submitted on 1 Sep 2010

HAL is a multi-disciplinary open access archive for the deposit and dissemination of scientific research documents, whether they are published or not. The documents may come from teaching and research institutions in France or abroad, or from public or private research centers.
L'archive ouverte pluridisciplinaire HAL, est destinée au dépôt et à la diffusion de documents scientifiques de niveau recherche, publiés ou non, émanant des établissements d'enseignement et de recherche français ou étrangers, des laboratoires publics ou privés. 


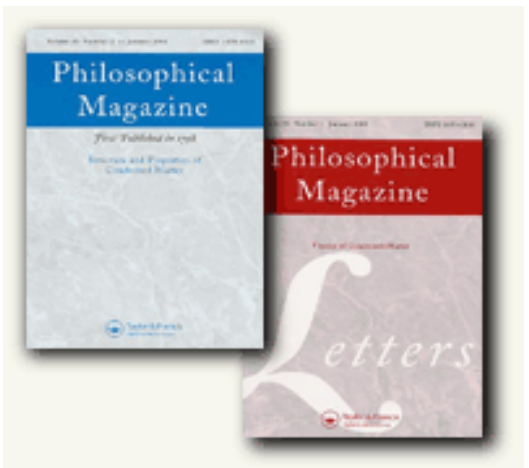

\section{Phase transformation of mixed $\operatorname{Cr}_{1-x} \mathbf{A l}_{x} \mathbf{N}$ nitride precipitates in ferrite}

\begin{tabular}{|r|l|}
\hline Journal: & Philosophical Magazine \& Philosophical Magazine Letters \\
\hline Manuscript ID: & TPHM-08-Oct-0368.R1 \\
\hline Journal Selection: & Philosophical Magazine \\
\hline Author: & 19-Dec-2008 \\
\hline Complete List of Authors: & $\begin{array}{l}\text { Clauss, Arno; Max Planck Institute for Metals Research, Prof. Dr Ir. } \\
\text { E.J. Mittemeijer } \\
\text { Bischoff, Ewald; Max Planck Institute for Metals Research, Prof. Dr } \\
\text { Ir. E.J. Mittemeijer } \\
\text { Schacherl, Ralf; Universität Stuttgart } \\
\text { Mittemeijer, Eric Jan; Max Planck Institute for Metals Research, } \\
\text { Prof. Dr Ir. E.J. Mittemeijer }\end{array}$ \\
\hline Keywords: & nitrides, transformations \\
\hline Keywords (user supplied): & nitriding, Fe-Cr-Al alloys, excess nitrogen \\
\hline &
\end{tabular}

\section{今scholarONE \\ Manuscript Central}


Manuscript No: THPM-08-Oct-0368

Dear Dr. Knowles,

we are very pleased with the promising remarks by the referee and that our manuscript has been recommended for publication.

The attached word documents provides our response to the few remarks made by the referee and includes precisely how we made the few modifications requested.

We hope that the paper can now definitively be accepted for publication.

Thank you very much for your time spent on this manuscript.

Yours Sincerely

Dr. Ralf Schacherl 
Response to the comments by the referee

- We now have included a couple of sentences in the introduction (p. 4 ,I. 8-11 and p.5, I.15-17) providing the broader perspective and repercussion of the work performed.

- A revised version of Ref. 13 has been submitted. The comments by the referees on the first version make it likely that the paper will definitively be accepted. Hence, it will be possible to indicate more precise publication details of Ref. 13. In the proofs of the current paper.

- The chemical potential of nitrogen in the inert gas atmosphere is nil. Hence a strong driving force exists to form $\mathrm{N}_{2}$ at the surface from dissolved nitrogen. This explains why some denitriding (outward diffusion of nitrogen) occurs during the anneal.

- One of the purposes of this paper was to reveal what happens with the excess nitrogen during annealing, expecting that it would diffuse to the unnitrided core, also in order to mimic a situation possibly occurring in practice. Homogeneous nitriding is only possible for very thin foils. Such specimens are employed by us for the investigation of nitrogen-absorption-isotherms (e.g. se Ref. 20). 
ARTICLE TYPE [ORIGINAL PAPER / MANUSCRIPT (REGULAR ARTICLE)]

Article Title [Phase transformation of mixed $\mathrm{Cr}_{1-x} \mathrm{Al}_{x} \mathrm{~N}$ nitride precipitates in ferrite] 


\title{
Phase transformation of mixed $\mathrm{Cr}_{1-x} \mathrm{Al}_{x} \mathrm{~N}$ nitride precipitates in ferrite
}

\author{
Arno R.. Clauss ${ }^{\mathrm{a}}$; Ewald Bischoff ${ }^{\mathrm{a}}$, Ralf E. Schacherl ${ }^{\mathrm{b} *}$ and Eric J. Mittemeijer ${ }^{\mathrm{a}, \mathrm{b}}$ \\ a Max Planck Institute for Metals Research, Heisenbergstr. 3, D-70569 Stuttgart, Germany; \\ ${ }^{\mathrm{b}}$ Institute for Physical Metallurgy, University of Stuttgart, Germany;
}

\section{Correspondence address:}

Dr. Ralf E. Schacherl

Institute for Physical Metallurgy, University of Stuttgart, Heisenbergstr. 3, D-70569 Stuttgart

Germany

Tel: +49-711-6893314 Fax: +49-711-6893312

e-mail: r.schacherl@mf.mpg.de

\section{E-mail addresses of all authors:}

Dr. Santosh S. Hosmani (s.hosmani@mf.mpg.de)

Dr. Ewalf Bischoff ( $\underline{\text { bischoff@,mf.mpg.de })}$

Dr. Ralf E. Schacherl (r.schacherl@mf.mpg.de)

Prof. Dr. Ir. Eric J. Mittemeijer (e.j.mittemeijer@mf.mpg.de)

*Corresponding author. Email: r.schacherl@mf.mpg.de 


\begin{abstract}
Nitriding of specimens with the composition $\mathrm{Fe}-1.5$ wt.\%Cr-1.5wt.\%Al (Fe-1.6at.\%Cr3.1at.\%Al) at $853 \mathrm{~K}$ leads to the formation of mixed, ternary $\mathrm{Cr}_{1-x} \mathrm{Al}_{x} \mathrm{~N}$ nitride platelets precipitated in the cubic, rock-salt structure type obeying a Bain-type orientation relationship with the ferrite matrix. Upon subsequent annealing (at $973 \mathrm{~K}$ ) the mixed, ternary nitrides transform into the two equilibrium, binary nitrides, namely $\mathrm{CrN}$ of cubic, rock-salt structure type in the Bain orientation relationship with the ferrite matrix and AlN of hexagonal, wurtzite structure type, obeying a Pitsch-Schrader orientation relationship with the ferrite matrix. At the same time the mobile excess nitrogen, dissolved in the ferrite matrix, diffuses towards the originally not nitrided core, where relatively coarse, cubic $\mathrm{CrN}$ and hexagonal AlN precipitates develop. The microstructure and (local) composition changes have been analysed by XRD, (HR)TEM, STEM, EDX and EPMA. It was found that the transformation proceeds by $\mathrm{Al}$ depletion of the original mixed $\mathrm{Cr}_{1-x} \mathrm{Al}_{x} \mathrm{~N}$ precipitates.
\end{abstract}

Keywords: nitriding; $\mathrm{Fe}-\mathrm{Cr}-\mathrm{Al}$ alloy; nitrides; transformations; excess nitrogen 


\section{Introduction; instability of nitrides}

Nitriding is a thermochemical surface engineering process that is widely used in industry to improve technical properties of ferritic steel workpieces like the resistance against fatigue, wear and corrosion [1-3]. Nitriding implies the introduction of nitrogen into the specimen/workpiece through its surface. Alloying elements like $\mathrm{Al}$ and $\mathrm{Cr}$ have a strong affinity for nitrogen and can form nitride precipitates in the ferrite matrix, which improves the mechanical strength drastically $[4,5]$.

Although nitriding has great industrial importance, the application practise is largely based on phenomenology. In particular $\mathrm{Al}$ and $\mathrm{Cr}$ are used together as alloying elements in typical nitriding steels. Hence, a strong technological interest stimulates the investigation of the composition, structure and shape of nitride precipitates in such multicomponent alloys.

Very often a gas mixture containing $\mathrm{NH}_{3}$ is used as nitriding medium. During gaseous nitriding the chemical activity of nitrogen dissolved in the specimen at its surface can be accurately adjusted by the so-called nitriding potential $r_{\mathrm{N}}=\frac{p_{\mathrm{NH}_{3}}}{p_{\mathrm{H}_{2}}^{3 / 2}}[6]$. By setting the value of the nitriding potential, the whether or not occurrence of a layer of iron nitrides at the surface, in addition to the formation of alloying-element nitrides in the ferritic matrix, can be controlled.

It should be realised that local (thermodynamic) equilibrium with the nitriding atmosphere can only be realised at the surface. As a matter of fact, beneath the surface the iron nitrides are metastable with respect to decomposition in iron and nitrogen gas (which leads to pore/channel formation along grain boundaries [6, 7]). Also the alloying-element nitrides developing in the ferritic substrate can be metastable. For example, the equilibrium modification of AIN is the hexagonal, wurtzite structure type. However, the nucleation of this thermodynamically stable structure is difficult in an annealed ferrite matrix $[4,8-11]$ and more easily nucleating metastable cubic, rock-salt structure type AlN precipitates occur, in particular in cold-rolled specimens. Transformation from such cubic AlN precipitates to 
hexagonal, wurtzite structure type AlN precipitates upon annealing of an $\mathrm{Fe}-\mathrm{Al}-\mathrm{N}$ alloy at $973 \mathrm{~K}$ was observed [12].

It was recently shown that upon nitriding a ternary $\mathrm{Fe}-\mathrm{Cr}-\mathrm{Al}$ alloy, $\mathrm{Cr}_{1-x} \mathrm{Al}_{x} \mathrm{~N}$ precipitates of the cubic, rock-salt structure type develop in the ferrite matrix [13]. The development of $\mathrm{Cr}_{1-x} \mathrm{Al}_{x} \mathrm{~N}$ precipitates is the consequence of kinetics: $\mathrm{Al}$ cannot precipitate separately as hexagonal, equilibrium $\mathrm{AlN}$ due to difficult nucleation. Instead mixed, cubic $\mathrm{Cr}_{1-x} \mathrm{Al}_{x} \mathrm{~N}$ precipitates of rock-salt structure type develop and cause a considerable (although not maximal) amount of energy release. Such mixed, ternary nitrides may be unstable with respect to decomposition into the thermodynamically stable binary nitrides, i.e. CrN of cubic, rock-salt structure type and AlN of hexagonal, wurtzite structure type.

The purpose of the present paper is to investigate the behaviour of these presumably metastable, mixed nitrides upon annealing. Does the mixed nitride decompose? Further, if AlN precipitates directly upon such annealing, which crystal structure does occur? Moreover, an accompanying effect of the annealing after the nitriding is a redistribution of the (mobile) excess nitrogen in the nitrided zone, which hitherto has not been investigated. From a scientific point of view this paper thus contributes to the understanding of the emergence and disappearance of intermediate precipitates in supersaturated solids.

\section{Experimental}

\subsection{Specimen preparation}

Specimens were prepared as described in Ref. [13]. The chemical composition and the amount of impurities were measured by chemical analysis (inductively coupled plasmaoptical emission spectroscopy, carrier gas hot extraction and combustion method). The thus determined alloy composition is shown in Table 1.

The element distribution (homogeneity) was proven by electron probe microanalysis. No segregation was observed. The recrystallised specimens with a dimension of $20 \times 15 \times 1 \mathrm{~mm}^{3}$ had an average grain diameter of $22 \mu \mathrm{m}$. 
Gaseous nitriding was performed in a vertical, multizone quartz-tube furnace at $853 \mathrm{~K}$ (cf. Ref. [13]). The gas fluxes of $\mathrm{H}_{2}$ and $\mathrm{NH}_{3}$ were adjusted by means of mass-flow controllers. The corresponding nitriding potential (cf. Refs. [6] and [7]) was $r_{\mathrm{N}}=0.104 \mathrm{~atm}^{-1 / 2}$. Under the chosen nitriding potential no iron nitrides develop at the surface, i.e. the nitrided layer consists only of the diffusion zone with nitride precipitates of the alloying elements.

After nitriding the specimens were annealed. To this end they were put in an $\mathrm{Al}_{2} \mathrm{O}_{3}$ crucible which was encapsulated in an evacuated quartz tube under a protective argon gas atmosphere (purity Ar: 99.999 vol.\%) with a pressure of $0.3 \mathrm{~atm}$ (equivalent to $1 \mathrm{~atm}$ at $973 \mathrm{~K})$. Subsequently the quartz tube was put into a muffle furnace at a temperature of about $973 \mathrm{~K}$. After $168 \mathrm{~h}$ annealing time the quartz tube was taken out of the furnace and cooled down to ambient temperature.

\subsection{Microstructural analysis}

Phase analysis by X-ray diffraction applied to the surface of all specimens before nitriding, after nitriding and after subsequent annealing was performed on both a PANalytical (formerly Philips) X'Pert Multi-Purpose Diffractometer (MPD) in Bragg-Brentano geometry and a PANalytical (formerly Philips) Materials-Research Diffractometer (MRD) with a quasiparallel beam geometry. Both diffractometers were equipped with graphite-diffracted beam monochromators set to $\mathrm{Co}-\mathrm{K} \alpha$ radiation. The specimens were rotated on a spinner around their vertical axis during each measurement, to improve crystal statistics. The diffraction angle $2 \theta$ was scanned over a range from $30^{\circ}$ until $140^{\circ}$ in steps of $0.05^{\circ}(\mathrm{MPD})$ and $0.04^{\circ}$ (MRD) with a counting time of $10 \mathrm{~s}$ (MPD) and $100 \mathrm{~s}$ up to $120 \mathrm{~s}$ (MRD) per step. Detected phases were identified by $2 \theta$ positions of their diffraction peaks in comparison with data from the ICDD data base [14].

Concentration depth profiles were determined by electron probe microanalysis (EPMA) performed on polished cross-sections. For light microscopy a piece of each nitrided and annealed specimen was cut off, embedded, ground, polished and etched with $2.5 \%$ Nital 
(2.5 vol.\% $\mathrm{HNO}_{3}$ in ethanol) at a temperature of about $323 \mathrm{~K}$ for about $200 \mathrm{~s}$. The microhardness was measured along the EPMA line-scans on the cross-sections of nitrided and annealed specimens. For details regarding the methods used for EPMA, light microscopy and microhardness measurements, see Ref. [13].

Transmission electron microscopy (TEM) was applied to investigate the (crystal) structure and morphology of the nitride precipitates in the nitrided and annealed specimens. For this purpose TEM samples were produced by either the jet-electropolishing technique or by argon ion milling (cf. Ref. [13] for details) from different depths of the nitrided and annealed zone. Specimens prepared by both preparation methods provide complementary insight (see Section 3.2). Two different precipitate crystal structures and orientation relationships (OR) with the ferrite matrix are relevant for the analyses of the selected area diffraction patterns (SADPs) in the present work:

(i) the Bain-type OR [15] (sometimes also called after Baker and Nutting [16]) between the bcc ferrite matrix and the nitride $(\mathrm{MeN})$ fcc rock-salt structure type precipitates

$$
\{001\}_{\alpha-\mathrm{Fe}} / /\{001\}_{\mathrm{MeN}},\langle 100\rangle_{\alpha-\mathrm{Fe}} / /\langle 110\rangle_{\mathrm{MeN}} ; \mathrm{Me}=\mathrm{Cr}, \mathrm{Al},
$$

(ii) the Pitsch-Schrader OR [17] between the bcc ferrite matrix and nitride (MeN) hcp wurtzite structure type precipitates

$$
\{110\}_{\alpha-\mathrm{Fe}} / /\{0001\}_{\mathrm{MeN}},\langle 001\rangle_{\alpha-\mathrm{Fe}} / /\langle 11 \overline{2} 0\rangle_{\mathrm{MeN}} ; \mathrm{Me}=\mathrm{Al} .
$$

Schematic SADPs with $[001]_{\alpha-\mathrm{Fe}}$ incident electron-beam axis pertaining to the two cases above are shown in Fig. 1. The experimentally recorded SADPs (cf. Section 3) exhibit additional spots at forbidden $100_{\alpha-\mathrm{Fe}}$ sites. These spots originate from $220_{\mathrm{Fe}_{3} \mathrm{O}_{4}}$ reflections due to unavoidable oxidation at the faces of the electron-transparent foils $[4,18,19]$.

Scanning transmission electron microscopy (STEM) was applied to get information about the chemical composition of individual nitride precipitates. High resolution transmission electron microscopy (HRTEM) was performed in particular to reveal the structure of the precipitate/matrix interfaces. For details of the instruments and techniques used, see Ref. [13]. 


\section{Results and discussion}

\subsection{Concentration depth and microhardness depth profiles; after nitriding and after}

\section{subsequent annealing}

EPMA concentration depth profiles of a nitrided $(15 \mathrm{~h}$ at $853 \mathrm{~K})$ and subsequently annealed $(168 \mathrm{~h}$ at $973 \mathrm{~K})$ specimen are shown in Fig. 2 a together with the corresponding LM micrograph. The depicted graph in Fig. 2 a consists of six graphically superimposed linescans, determined at different locations on the cross-section perpendicular to the specimen surface. The dashed vertical white lines denote the depths from which TEM samples were prepared. The dotted horizontal black line denotes the so-called normal amount of $\mathrm{N}$ (i.e. $[\mathrm{N}]_{\text {normal }}$ ), which is necessary to transform all alloying elements (Al and $\mathrm{Cr}$ substitutionally dissolved in ferrite) into $\mathrm{AlN}, \mathrm{CrN}$ and/or mixed $\mathrm{Cr}_{1-x} \mathrm{Al}_{x} \mathrm{~N}$ precipitates (i.e. $[\mathrm{N}]_{\mathrm{MeN}}$ ) plus the amount of $\mathrm{N}$, which can be dissolved interstitially in the remaining pure, unstrained ferrite matrix in thermodynamic equilibrium with the nitriding gas atmosphere at the applied nitriding conditions (i.e. $[\mathrm{N}]_{\alpha-\mathrm{Fe}}^{0}=0.30$ at.\% in pure ferrite [20]). The amount of $\mathrm{N}$ in excess of this normal amount is called "excess" nitrogen [20-23].

During nitriding of an $\mathrm{Fe}-1.5 \mathrm{wt} . \% \mathrm{Cr}-1.5 \mathrm{wt} . \% \mathrm{Al}$ specimen for $15 \mathrm{~h}$ at $853 \mathrm{~K}$ cracks develop along grain boundaries, in particular those running more or less from the surface towards the specimen centre (cf. the LM micrograph in Fig. 2 a); the nitrided layer is brittle. The nitrided zone before annealing ranges until a depth of about $360 \mu \mathrm{m}$ (cf. Fig. 2 b). After annealing the nitrogen is, overall, distributed more or less evenly over the cross-section of the specimen, except near the surface where the nitrogen concentration decreases towards the outer surface as a consequence of outward diffusion of $\mathrm{N}$ during annealing (see the EPMA concentration depth profiles in Figs. $2 \mathrm{a}$ and b). In the initially unnitrided core the $\mathrm{N}$ and $\mathrm{Cr}$ atomic concentrations scatter strongly after the annealing (see, for $\mathrm{N}, \mathrm{Cr}$ and $\mathrm{Al}$, at the "specimen centre" area in Fig. 2 a and for $\mathrm{N}$ also in Fig. 2 b). 
As can be concluded from the difference between the $\mathrm{N}$ concentration depth profiles after only nitriding and after nitriding plus annealing (Fig. 2 b), during annealing the mobile excess (i.e. dissolved in the $\alpha$-Fe matrix) nitrogen apparently diffuses towards the formerly not nitrided core. After the annealing the amount of nitrogen remaining in the former diffusion zone is still higher than the "normal" amount of nitrogen (cf. dotted horizontal black line in Fig. 2 a). This is ascribed to the presence of immobile excess nitrogen, which is trapped at the precipitate/matrix interface (cf. Ref. [13]).

After EPMA the embedded cross-section was etched to uncover the trace of the electron beam line-scan. Along such an EPMA line-scan the microhardness values were determined to get a microhardness depth profile. The $\mathrm{N}$ atomic concentration depth profiles of a specimen after nitriding and of a specimen after subsequent annealing together with the corresponding microhardness depth profiles are shown in Fig. 2 b. In view of the different widths of the cross sections of the two specimens, the centre line of the nitrided specimen was made coincident with the centre line of the nitrided plus annealed specimen. It follows that the microhardness depth profiles and the corresponding $\mathrm{N}$ concentration depth profiles have the same characteristic course, except in the core of the annealed specimen, where the $\mathrm{N}$ concentration scatters strongly, and the hardness values are only slightly increased as compared to the hardness increase observed upon nitriding in the initially nitrided zone, with reference to the formerly unnitrided core. The maximum Vickers microhardness at the nitrided specimen surface of about $1200 \mathrm{HV} 0.015$ had decreased upon annealing to a value of about $600 \mathrm{HV} 0.015$. The decrease of the microhardness during annealing, in particular in the near-surface region, indicates a coarsening and/or a transformation of the initially platelet-like (semi)coherent $\mathrm{Cr}_{1-x} \mathrm{Al}_{x} \mathrm{~N}$ precipitates. The microhardness in the unnitrided core of about $150 \mathrm{HV} 0.015$ had increased to about $300 \mathrm{HV} 0.015$ upon annealing. This microhardness increase in the formerly unnitrided core is due to inward diffusion of excess nitrogen and the formation of relatively coarse and incoherent equilibrium nitride precipitates (cf. Section 3.2.3), which explains the scatter in the N, Cr and Al concentrations in this region. 


\subsection{Precipitates after nitriding and after subsequent annealing; structure, composition and orientation relationships}

\subsubsection{Near the surface}

X-ray diffraction analyses were carried out on specimen surfaces before nitriding, after nitriding and after subsequent annealing; the corresponding diffractograms are shown in Fig. 3 a. No new phase is identifiable in the diffractogram after nitriding. However, a strong broadening of the ferrite-matrix reflections is apparent. This is due to the presence of tiny nitride precipitates, which diffract coherently with the ferrite matrix (see Ref. [24]). TEM and STEM-EDX analyses have shown that these precipitates are mixed $\mathrm{Cr}_{1-x} \mathrm{Al}_{x} \mathrm{~N}$ nitrides [13].

Annealing after nitriding leads to strong decrease of the line broadening of the ferritematrix reflections. Also some tiny intensity humps occur at the low-angle side of the $\alpha$-Fe 110 reflection in the X-ray diffractograms; see Fig. 3 b. The intensity humps can be assigned to reflections from hexagonal AlN in the wurtzite structure that evidently diffracts incoherently with respect to the ferrite matrix. The presence of cubic, rock-salt AlN nitride and cubic, rocksalt CrN nitride cannot be verified because of overlap of corresponding nitride reflections with ferrite reflections. Therefore TEM analysis was performed next.

A BF image of a jet-electropolished TEM sample from near the surface (cf. Fig. 2 a), together with corresponding SADPs and EDX spectra, is shown in Fig. 4. "Round" particles are visible. The dissolution of the ferrite matrix during jet-electropolishing leads partially to "loosening" of the nitride particles (see the round particles in Fig. 4) and a distinct OR with the matrix then no longer occurs. The dark round particles on the BF image were big enough to get a separate SADP of mainly such a particle. By means of the measured lattice spacings in combination with the results from the EDX spectra (compare counting rate for $\mathrm{Cr}$ in the "matrix" spectrum and in the "round particle" spectrum; the Fe counts in the particle spectrum are from the surrounding matrix), the round particles can be identified as cubic, rock-salt structure type $\mathrm{CrN}$. 
An HRTEM image of an ion-milled TEM sample from near the surface (cf. Fig. 2 a) is shown in Fig. 5. By this type of TEM specimen preparation the cohesion of nitride particles and matrix is maintained, in contrast with the jet-electropolishing technique (see above). In the dotted square A a roundish precipitate can be recognised (cf. white arrow) whereas in the solid square B two differently oriented smaller, more platelet-like precipitates are visible (cf. white arrows), which are perpendicular to each other. Fast Fourier transformation (FFT) patterns have been generated from selected regions from the square areas A and B. The FFT pattern of area A is congruent with the Pitsch-Schrader OR whereas the FFT pattern of area B is congruent with the Bain OR (cf. Fig. 1).

For the determination of the chemical composition of the nitride precipitates in the ionmilled foils, EDX line-scans were recorded by STEM. A STEM BF image of three adjacent grains in an ion-milled sample from the nitrided and annealed specimen near the surface is shown in Fig. 6, together with the results of the STEM line-scans (EDX), along paths indicated by the arrows $\mathrm{b}$ and $\mathrm{c}$ in the BF image. The drift of the samples imposed a practical limit on the counting time, and therefore, in contrast with the successful recording of the $\mathrm{Cr}$ and Al line-scans shown in the figure, a reliable nitrogen line-scan could not be obtained (for details of the quantitative analysis see Ref. [13]).

Along the grain boundaries and at the triple junction shown in Fig. 6 relatively large particles are visible with bright contrast. STEM line-scan b crosses such a particle. The linescan reveals the distinct presence of $\mathrm{Al}$, and not of $\mathrm{Cr}$, in the particle. Such bright but smaller precipitates are also visible inside the grains. The STEM line-scan c across such a smaller precipitate shows a similar result like that for the bigger particle.

The above results, combined XRD and TEM, can be summarised: after annealing the microstructure in the near surface region reveals the presence of cubic, rock-salt structure type chromium-rich precipitates (“CrN") and hexagonal, wurtzite structure type aluminium-rich precipitates (“AlN"). The particle size varies from $10 \mathrm{~nm}$ to $50 \mathrm{~nm}$ and more; the thickness of the initial $\mathrm{Cr}_{1-x} \mathrm{Al}_{x} \mathrm{~N}$ platelets is 1-2 $\mathrm{nm}$ [13]. The cubic precipitates exhibit a Bain OR with the 
ferrite matrix, the hexagonal precipitates show a Pitsch-Schrader OR with the ferrite matrix. These results imply that in the near-surface region the initially present cubic, rock-salt structure type $\mathrm{Cr}_{1-x} \mathrm{Al}_{x} \mathrm{~N}$ precipitates are replaced by $\mathrm{AlN}$ and $\mathrm{CrN}$ upon sufficiently long annealing after nitriding.

\subsubsection{In the nitrogen diffusion zone}

A TEM BF image and corresponding DF images from an ion-milled sample, taken from the diffusion zone at a depth of about $215 \mu \mathrm{m}$ (cf. Fig. 2 a), are shown in Fig. 7. The zone axis (incident electron-beam direction) is $[001]_{\alpha-\mathrm{Fe}}$. Two kinds of precipitates are visible in the BF image and as evidenced by the SADP and DF images: (i) platelet-like cubic, rock-salt structure type precipitates (largely viewed edge-on for the operating zone axis of the ferrite matrix) possessing a Bain-type OR with the ferrite matrix and (ii) coarser hexagonal, wurtzite structure type precipitates exhibiting the Pitsch-Schrader OR with the ferrite matrix (cf. Fig. 7 and the SADP shown as inset in Fig. 7); see in particular the corresponding DF images taken from a rock-salt $002_{\mathrm{MeN}}$ spot (Fig. 7 b) and a wurtzite $0002_{\mathrm{MeN}}$ or $1 \overline{1}_{00_{\mathrm{MeN}}}$ (cannot be distinguished; cf. Fig. 1) spot (Fig. 7 c) indicated by circles in the SADP. The bright platelets in the DF image of Fig. $7 \mathrm{~b}$ are not exactly parallel and there is a variation in the brightness inside the platelets. Apparently deviations of the Bain OR occur along a platelet, which is compatible with the slight splitting up of the $002_{\mathrm{MeN}}$ rock-salt spots in the SADP (cf. Ref. [13]). In the BF image the strain-field contrast around the precipitates is not pronounced, as compared to BF images from the same depth of the nitrided zone before annealing (cf. Ref. [13]).

A BF image recorded by STEM on an ion-milled sample, taken from the nitrided and annealed specimen at the same depth of about $215 \mu \mathrm{m}$, is shown in Fig. 8 a. Two kinds of precipitates are visible with different orientation: bright particles and dark particles. The results of the STEM line-scans (EDX) shown in Figs. $8 \mathrm{~b}$ and c reveal that the bright particle b contains Al but no $\mathrm{Cr}$, whereas the dark particle c contains both elements, $\mathrm{Cr}$ and $\mathrm{Al}$. Hence, 
precipitates of the mixed $\mathrm{Cr}_{1-x} \mathrm{Al}_{x} \mathrm{~N}$ cubic, rock-salt structure type are (still) present in the ferrite matrix at this depth (dark precipitate in Fig. 8 a). However, the Al content of the mixed $\mathrm{Cr}_{1-x} \mathrm{Al}_{x} \mathrm{~N}$ nitride pertaining to the line-scan in Fig. $8 \mathrm{c}$ appears to be decreased distinctly compared with STEM line-scan results from the nitrided specimen before annealing (cf. Fig. $7 \mathrm{~b}$ in Ref. [13]): Al depletion in $\mathrm{Cr}_{1-x} \mathrm{Al}_{x} \mathrm{~N}$ has occurred due to the formation of the hexagonal, wurtzite AlN upon annealing.

The above results suggest that the replacement of the initial cubic $\mathrm{Cr}_{1-x} \mathrm{Al}_{x} \mathrm{~N}$ precipitates by (equilibrium) cubic $\mathrm{CrN}$ and hexagonal $\mathrm{AlN}$ precipitates, proceeds by $\mathrm{Al}$ depletion of the initial $\mathrm{Cr}_{1-x} \mathrm{Al}_{x} \mathrm{~N}$ precipitates, which eventually become $\mathrm{CrN}$, under simultaneous coarsening.

\subsubsection{In the initially unnitrided core}

Excess nitrogen from the original nitrogen diffusion zone diffuses upon annealing inwardly and brings about a "nitriding" of the initially unnitrided core (cf. Fig. 2 and its discussion in Section 3.1). An EPMA concentration depth profile in the region of the specimen centre (before annealing: the unnitrided core) of an annealed specimen, together with the corresponding scanning electron microscopy (SEM) image, is shown in Fig. 9. The white arrow shows the trace of the line-scan. The dashed vertical lines denote points where the electron beam crossed black particles, which evidently led to local, abrupt increases of the $\mathrm{N}$ and $\mathrm{Cr}$ concentrations. These black particles, thus likely $\mathrm{CrN}$, occur mainly along grain boundaries of the ferrite matrix and only sporadically within the grains. The Al concentration shows also a larger variation in the originally unnitrided core, as compared to the originally nitrided zone and the unnitrided state, but much less pronounced as for the $\mathrm{Cr}$ and $\mathrm{N}$ concentrations: apparently a distinctly preferred precipitation of AlN at grain boundaries does not occur (see what follows).

XRD phase analysis of the core region was carried out, with a high counting time, by recording an X-ray diffractogram from the surface obtained after material removal from one side of the specimen by grinding and polishing. The thus obtained diffractogram is shown in Fig. 10. Sharp reflections are visible, in addition to the ferrite-matrix reflections, the positions 
of which agree well with corresponding data from the ICDD data base [14] for both the hexagonal AlN wurtzite structure type phase and the cubic $\mathrm{CrN}$ rock-salt structure type phase. The presence of cubic, rock-salt structure type AlN cannot be excluded since the important possible reflections suffer from severe overlap with ferrite and $\mathrm{CrN}$ reflections.

A BF image and the corresponding SADP (electron-beam axis: [001 $]_{\alpha-\mathrm{Fe}}$ ) of an ion-milled TEM sample taken from the specimen centre are shown in Fig. 11. Besides ferrite (and $220_{\mathrm{Fe}_{3} \mathrm{O}_{4}}$; cf. Section 2.3) spots, only AlN wurtzite structure type spots, indicating a PitschSchrader OR of the precipitate with the ferrite matrix (cf. Fig. 1), can be observed in the SADP. The AlN precipitates in Fig. 11 appear bright in the ferritic matrix due to the considerable difference in atomic number of $\mathrm{Al}$ (precipitate) and $\mathrm{Fe}$ (matrix). The atomic numbers of $\mathrm{Cr}$ and $\mathrm{Fe}$ are not so different and hence a low contrast between chromium-rich precipitates and the ferrite matrix is expected: it is hardly possible to identify chromium-rich precipitates in Fig. 11.

In order to characterise the precipitates by their chemical composition a STEM line-scan (EDX) was carried out across a bright precipitate (Figs. $12 \mathrm{a}$ and b). In this bright particle only Al is detectable, but no Cr. Another STEM line-scan was carried out across a hardly visible precipitate (Figs. $12 \mathrm{c}$ and d). In this precipitate only $\mathrm{Cr}$ is detectable, and not $\mathrm{Al}$.

A STEM BF image and EDX elemental maps for $\mathrm{N}-\mathrm{K}, \mathrm{Al}-\mathrm{K}$ and $\mathrm{Cr}-\mathrm{K}$ at this location are shown in Fig. 13. The aluminium-rich (also nitrogen-rich) areas can clearly be assigned to the bright (AlN) precipitates in the BF image. The chromium-rich area (also nitrogen-rich) cannot be assigned to a distinct contrast in the $\mathrm{BF}$ image: $\mathrm{CrN}$ precipitates are hardly visible in the BF images (see above).

From the above results it is concluded that the bright particles consist of the hexagonal, equilibrium AlN wurtzite structure type, whereas the dark, hardly visible particles consist of the cubic, equilibrium $\mathrm{CrN}$ rock-salt structure type. There is no indication for the presence of the mixed, metastable $\mathrm{Cr}_{1-x} \mathrm{Al}_{x} \mathrm{~N}$ nitride as an intermediate precipitation stage. 
It follows that during annealing after nitriding in the originally unnitrided core relatively coarse (size $100 \mathrm{~nm}$ to $200 \mathrm{~nm}$ ) hexagonal, wurtzite structure type AlN and cubic, rock-salt structure type $\mathrm{CrN}$ precipitates develop in the grain interiors; mixed $\mathrm{Cr}_{1-x} \mathrm{Al}_{x} \mathrm{~N}$ precipitates are not observed.

\section{Conclusions}

(i) Upon nitriding (here at $853 \mathrm{~K}$ ) ferritic iron-based $\mathrm{Fe}-\mathrm{Cr}-\mathrm{Al}$ alloy, mixed, metastable cubic, rock-salt structure type $\mathrm{Cr}_{1-x} \mathrm{Al}_{x} \mathrm{~N}$ nitrides develop in the nitrided zone, which contains considerably more nitrogen than necessary to precipitate all $\mathrm{Cr}$ and all $\mathrm{Al}$ : excess nitrogen.

(ii) In the nitrided zone, annealing (here at $973 \mathrm{~K}$ ) subsequent to nitriding leads to the development of the equilibrium precipitates $\mathrm{CrN}$ and $\mathrm{AlN}$ :

- Cubic, rock-salt structure type and hexagonal, wurtzite structure type particles occur after annealing, which exhibit a Bain-type orientation relationship and a Pitsch-Schrader orientation relationship, respectively, with the ferrite matrix, and which correspond with (compositional analysis) $\mathrm{CrN}$ and $\mathrm{AlN}$, respectively. Part of the cubic, rock-salt structure type particles is (still) mixed $\mathrm{Cr}_{1-x} \mathrm{Al}_{x} \mathrm{~N}$ nitride, however containing less $\mathrm{Al}$ than initially present.

- Transformation of the initial mixed $\mathrm{Cr}_{1-x} \mathrm{Al}_{x} \mathrm{~N}$ nitrides proceeds by their $\mathrm{Al}$ depletion. The subsequent precipitation of AlN occurs in the interior and at grain boundaries of the matrix. A coarser microstructure results.

- The precipitates no longer exhibit strong coherency with the ferrite matrix, as reflected by the strong decrease of the broadening of the XRD ferrite-matrix reflections and the distinct decrease of hardness.

(iii) In the originally unnitrided core, annealing leads to the presence of nitrogen by diffusion of the mobile excess nitrogen from the nitrided zones. This nitrogen immediately precipitates as relatively coarse $\mathrm{CrN}$ at grain boundaries and as smaller ( $\sim 100 \mathrm{~nm}$ to $200 \mathrm{~nm})$ cubic, rocksalt structure type $\mathrm{CrN}$ and hexagonal, wurtzite structure type $\mathrm{AlN}$ in the interior of the grains. Mixed $\mathrm{Cr}_{1-x} \mathrm{Al}_{x} \mathrm{~N}$ nitride does not develop. 


\section{Acknowledgements}

The authors wish to thank Mr. J. Köhler and Mr. P. Kress for assistance with the nitriding experiments, Mrs. S. Haug for assistance with the EPMA experiments, Mr. W.-D. Lang for TEM sample preparation, Mrs. M. Kelsch for assistance during the first stage of TEM experiments, Dr. F. Phillipp for assistance during the first stage of HRTEM experiments, Dr. W. Sigle for assistance during the STEM experiments, discussion and critical reading of the manuscript, and Dr. A. Leineweber for discussion.

\section{References}

[1] C.H. Knerr, T.C. Rose, J.H. Filkowski Gas nitriding. In: J.R. Davis, G.M. Davidson, S.R. Lampman, T.B. Zorc, J.L. Daquila, A.W. Ronke, K.L. Henniger, R.C. Uhl, editors. ASM Handbook: Heat Treating, vol. 4. Metals Park, Ohio: ASM International, 1991. p.387.

[2] E.J. Mittemeijer, J. Grosch, editors. Proceedings of 'AWT-Tagung Nitrieren und Nitrocarburieren'. Wiesbaden: Arbeitsgemeinschaft Wärmebehandlung und Werkstofftechnik e.V., 1991.

[3] D. Liedtke, U. Baudis, J. Boßlet, U. Huchel, H. Klümper-Westkamp, W. Lerche, H.J. Spies. Wärmebehandlung von Eisenwerkstoffen Nitrieren und Nitrocarburieren. Renningen: Expert Verlag, 2006.

[4] M.H. Biglari, C.M. Brakman and E.J. Mittemeijer, Phil Mag 72A (1995), p. 1281.

[5] K.H. Jack In: Proceedings of the conference on heat tratment 1973. London: The metals society, 1975. p.39.

[6] E.J. Mittemeijer and J.T. Slycke, Surf Eng 12 (1996), p. 152.

[7] E.J. Mittemeijer and M.A.J. Somers, Surf Eng 13 (1997), p. 483.

[8] H.H. Podgurski and H.E. Knechtel, Trans TMS-AIME 245 (1969), p. 1595.

[9] M.H. Biglari, C.M. Brakman, M.A.J. Somers, W.G. Sloof and E.J. Mittemeijer, Z Metallk 84 (1993), p. 124. 
[10] M.H. Biglari, C.M. Brakman, E.J. Mittemeijer and S. van der Zwaag, Metall Mater Trans 26A (1995), p. 765.

[11] J.S. Steenaert, M.H. Biglari, C.M. Brakman, E.J. Mittemeijer and S. van der Zwaag, Z Metallk 86 (1995), p. 700.

[12] M. Sennour and C. Esnouf, Acta Mater 51 (2003), p. 943.

[13] A.R. Clauss, E. Bischoff, S.S. Hosmani, R.E. Schacherl and Mittemeijer EJ. submitted for publication.

[14] JCPDS-International Centre for Diffraction Data, 2002.

[15] E.C. Bain, Trans AIME 70 (1924), p. 25.

[16] R.G. Baker and J. Nutting,. Iron and Steel Inst Spec Rep 64 (1959), p. 1.

[17] W. Pitsch and A. Schrader,. Arch Eisenhüttenw 29 (1958), p. 715.

[18] S. Chen and J. Morris, Metall Mater Trans 8A (1977), p. 19.

[19] M. Sennour, P.H. Jouneau and C.J. Esnouf, J Mater Sci 39 (2004), p. 4521.

[20] S.S. Hosmani, R.E. Schacherl and E.J. Mittemeijer, Acta Mater 54 (2006), p. 2783.

[21] P.M. Hekker, H.C.F. Rozendaal and E.J. Mittemeijer, J Mater Sci 20 (1985), p. 718.

[22] M.A.J. Somers, R.M. Lankreijer and E.J. Mittemeijer, Phil Mag 59A (1989), p. 353.

[23] M.H. Biglari, C.M. Brakman, E.J. Mittemeijer and S. van der Zwaag, Phil Mag 72A (1995), p. 931.

[24] N.E. Vives Diaz, S.S. Hosmani, R.E. Schacherl and E.J. Mittemeijer, Acta Mater (2008);in press doi:10.1016/j.actamat.2008.04.041. 


\section{Figure captions}

Fig. 1: Schematic SADPs with $[001]_{\alpha-\mathrm{Fe}}$ incident electron-beam axis pertaining to the Bain orientation relationship (OR) between cubic, rock-salt structure type precipitates and the ferrite matrix (including superposition of all variants) and of the Pitsch-Schrader OR between hexagonal, wurtzite structure type precipitates and the ferrite matrix (for clarity here only one variant is shown).

Fig. 2: (a) EPMA concentration depth profiles of a nitrided and annealed specimen together with the corresponding LM micrograph. The dashed vertical white lines indicate the depths at which TEM samples were prepared. The dotted horizontal black line represents the normal amount of $\mathrm{N}$ (see text). (b) Comparison of the microhardness depth profiles and the $\mathrm{N}$ concentration depth profiles of both an only nitrided specimen and a nitrided and subsequently annealed specimen. The centre lines of both specimens have been made coincident.

Fig. 3: (a) X-ray diffractograms taken from the specimen surface before nitriding, after nitriding and after nitriding and annealing (counting time $10 \mathrm{~s} / \mathrm{step}$ ). After nitriding a very pronounced peak broadening occurs, which becomes reduced upon subsequent annealing. (b) X-ray diffractogram of the specimen surface after nitriding and annealing recorded applying longer counting times (100 s/step) than in Fig. 3 a in order to identify the intensity humps at the low-angle side of the $\alpha$-Fe 110 reflection. Small peaks from the hexagonal AIN wurtzite structure can be observed. Presence or absence of peaks from the cubic-rock salt structure type AlN and $\mathrm{CrN}$ cannot be confirmed, because they generally are subject to strong overlapping with ferrite-matrix reflections. 
Fig. 4: BF image of a jet-electropolished TEM sample from the nitrided and annealed specimen near the surface, together with corresponding SADPs (electron-beam axis near $[001]_{\alpha-\mathrm{Fe}}$ ) and EDX spectra of the ferrite matrix and precipitate (round particle).

Fig. 5: HRTEM image of an ion-milled TEM sample from the nitrided and annealed specimen near the surface (electron-beam axis: $[001]_{\alpha-\mathrm{Fe}}$ ). The FFT patterns generated from an area with the roundish precipitate in the dotted square A and from an area with platelet-like precipitates in the solid square B are shown at the right. The roundish particle in A exhibits a Pitsch-Schrader OR with the ferrite matrix, whereas the more platelet-like particles in B satisfy the Bain OR with the ferrite matrix (cf. Fig. 1).

Fig. 6: (a) STEM BF image of three adjacent grains with triple junction in an ion-milled sample from the nitrided and annealed specimen near the surface and the results of STEM line-scans along paths (b) and (c) (see arrows).

Fig. 7: (a) BF image and corresponding SADP of an ion-milled TEM sample from a nitrided and annealed specimen taken at a depth of about $215 \mu \mathrm{m}\left(\right.$ electron-beam axis: $\left.[001]_{\alpha-\mathrm{Fe}}\right)$. (b) DF image obtained from a $002_{\mathrm{MeN}}$ spot of rock-salt structure type precipitates having a Bain OR with the ferrite matrix. (c) DF image obtained from a $0002_{\mathrm{MeN}}$ or $1 \overline{1} 00_{\mathrm{MeN}}$ (cannot be distinguished; cf. Fig. 1) spot of the wurtzite structure type precipitates exhibiting a PitschSchrader OR with the ferrite matrix (for analysing the SADP, see Fig. 1).

Fig. 8: (a) STEM BF image of an ion-milled TEM sample from a nitrided and annealed specimen taken at a depth of about $215 \mu \mathrm{m}$ showing two precipitates with different contrast. 
The image quality is poor because of the ferromagnetism of the material. (b) Results of the STEM line-scan of the bright precipitate in Fig. 8 a (see arrow). (c) Results of the STEM linescan of the dark precipitate in Fig. 8 a (see arrow).

Fig. 9: EPMA concentration depth profile from the region around the specimen centre (initially the unnitrided core) after nitriding and subsequent annealing, together with the corresponding SEM micrograph. The white arrow indicates the course of the line-scan. The dashed vertical black lines denote points where the electron beam hit black particles mostly at matrix grain boundaries, which exhibit a local concentration increase of $\mathrm{N}$ and $\mathrm{Cr}$.

Fig. 10: X-ray diffractogram of the specimen centre (formerly unnitrided core, i.e. at about $500 \mu \mathrm{m}$ depth) for phase analysis after nitriding and annealing (counting time $120 \mathrm{~s} / \mathrm{step}$ ).

Fig. 11: BF image and corresponding SADP of an ion-milled TEM sample from a nitrided and annealed specimen taken at the specimen-centre area (initially the unnitrided core) showing coarse, wurtzite structure type precipitates, exhibiting a Pitsch-Schrader OR with the ferrite matrix (see SADP (inset; electron-beam axis: [001 $]_{\alpha-\mathrm{Fe}}$ ) and cf. Fig. 1).

Fig. 12: (a) and (c) STEM BF images of an ion-milled TEM sample from a nitrided and annealed specimen taken at the specimen-centre area (initially the unnitrided core). (b) and (d) Results of the corresponding STEM line-scans (EDX; see arrows in Figs. 12 a and c). Figs. 12 a and b: only $\mathrm{Al}$ is detectable in the bright precipitate. Figs. $12 \mathrm{c}$ and $\mathrm{d}$ : only $\mathrm{Cr}$ is detectable in the hardly visible precipitate.

Fig. 13: (a) STEM BF image of an ion-milled sample from a nitrided and annealed specimen taken at the specimen-centre area (the formerly unnitrided core) and the results of element 
mapping for intensities of $\mathrm{N}-\mathrm{K}, \mathrm{Al}-\mathrm{K}$ and $\mathrm{Cr}-\mathrm{K}$ : (b), (c) and (d) respectively. The bright precipitates can clearly be interpreted as $\mathrm{AlN}$, whereas the $\mathrm{CrN}$ precipitate is hardly visible in the BF image. 
Table 1

Amounts of alloying elements and impurities of the used alloy

\begin{tabular}{|l|cc|cc|l|l|l|l|}
\hline Alloy & \multicolumn{2}{|c|}{$\mathrm{Cr}$} & \multicolumn{2}{|c|}{$\mathrm{Al}$} & $\mathrm{N}$ \\
& (wt.\%) & (at.\%) & (wt.\%) & (at.\%) & (wt.\%) & (wt.\%) & $\begin{array}{l}\mathrm{S} \\
\text { (wt.\%) }\end{array}$ & $\begin{array}{l}\text { C } \\
\text { (wt.\%) }\end{array}$ \\
\hline $\mathrm{Fe}-\mathrm{Cr}-\mathrm{Al}$ & $1.52 \pm 0.01$ & $1.60 \pm 0.01$ & $1.52 \pm 0.01$ & $3.09 \pm 0.02$ & $<0.0005$ & $0.0043 \pm 0.0004$ & $<0.0010$ & $0.0025 \pm 0.0002$ \\
\hline
\end{tabular}


$\mathrm{bcc}_{\text {matrix }}-\mathrm{fCc}_{\text {nitride }}$

\section{Bain OR:}

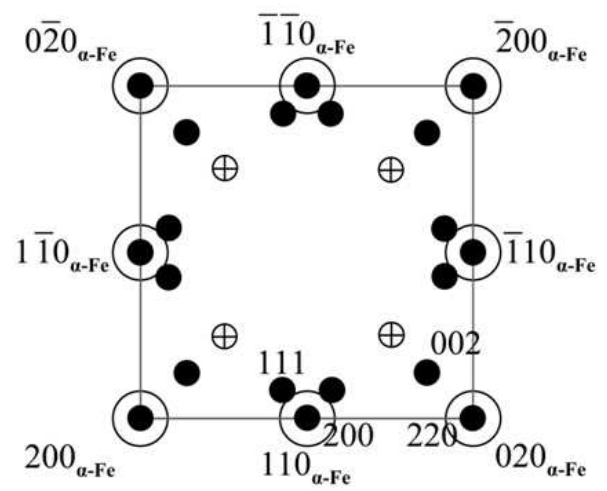

\section{$\mathrm{bcc}_{\text {matrix }}-\mathrm{hcp}_{\text {nitride }}$}

\section{Pitsch-Schrader OR:}

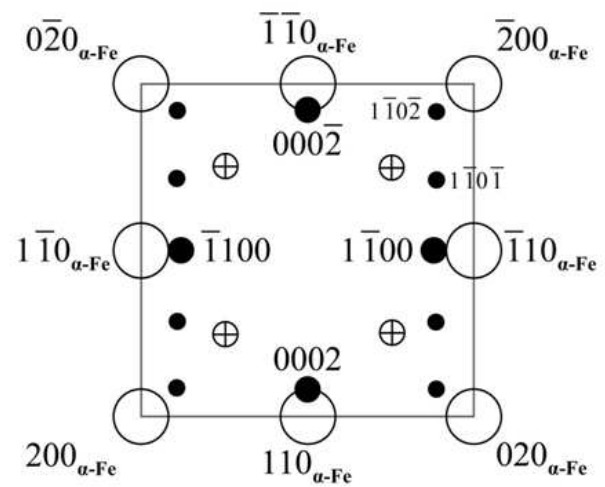

$\alpha-\mathrm{Fe}$

- $\mathrm{MeN}$

$\oplus \mathrm{Fe}_{3} \mathrm{O}_{4}$

Fig. 1: Schematic SADPs with [001] $\boldsymbol{\alpha}_{\text {-Fe }}$ incident electron-beam axis pertaining to the Bain orientation relationship (OR) between cubic, rock-salt structure type precipitates and the ferrite matrix (including superposition of all variants) and of the Pitsch $\square$ Schrader OR between hexagonal, wurtzite structure type precipitates and the ferrite matrix (for clarity here only one variant is shown). $\alpha \boldsymbol{\alpha}$ $160 \times 118 \mathrm{~mm}(150 \times 150 \mathrm{DPI})$ 
(a)
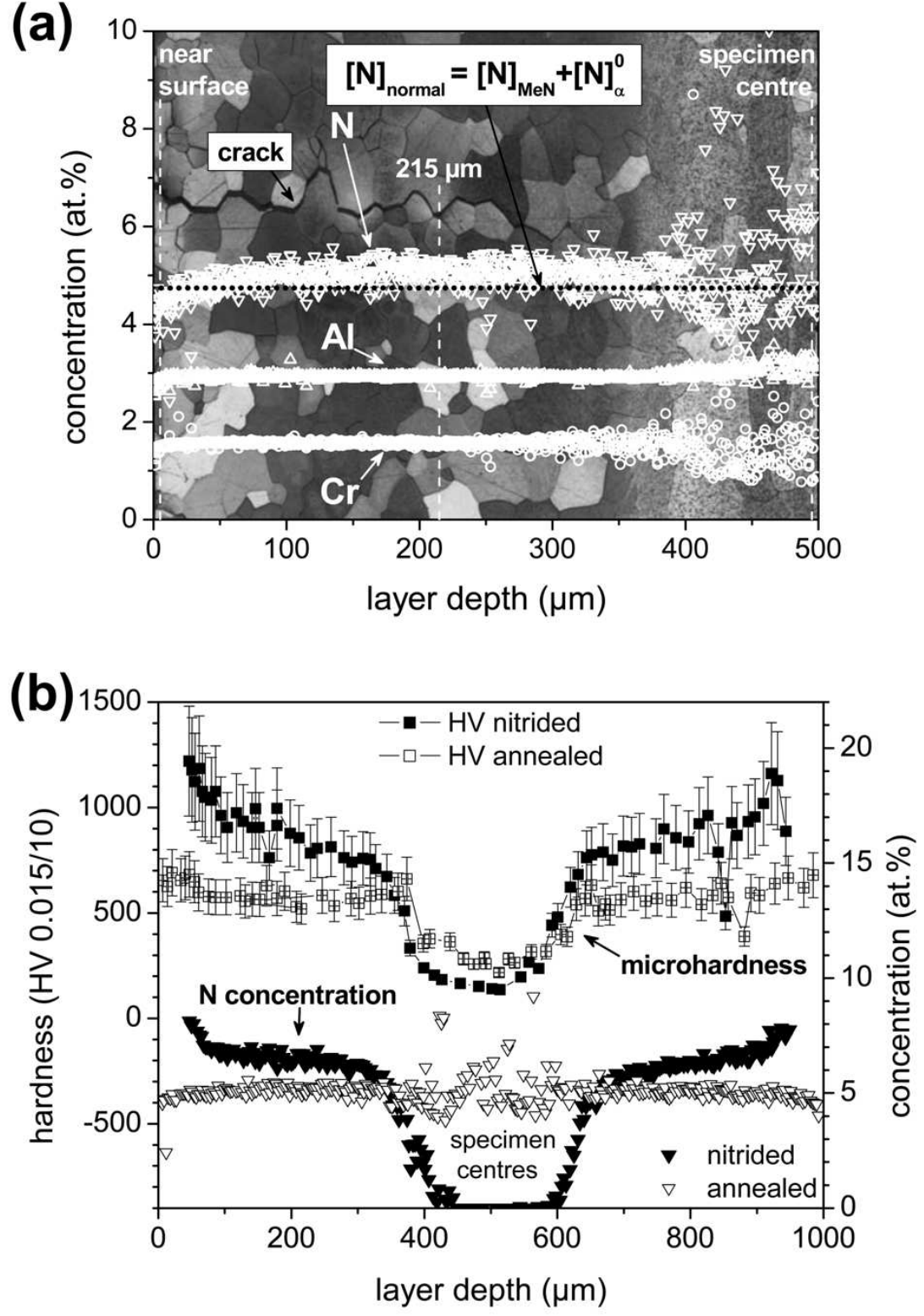

Fig. 2: (a) EPMA concentration depth profiles of a nitrided and annealed specimen together with the corresponding LM micrograph. The dashed vertical white lines indicate the depths at which TEM samples were prepared. The dotted horizontal black line represents the normal amount of $\mathrm{N}$ (see text). (b)Comparison of the microhardness depth profiles and the $\mathrm{N}$ concentration depth profiles of both an only nitrided specimen and a nitrided and subsequently annealed specimen. The centre lines of both specimens have been made coincident. $160 \times 230 \mathrm{~mm}(150 \times 150 \mathrm{DPI})$ 


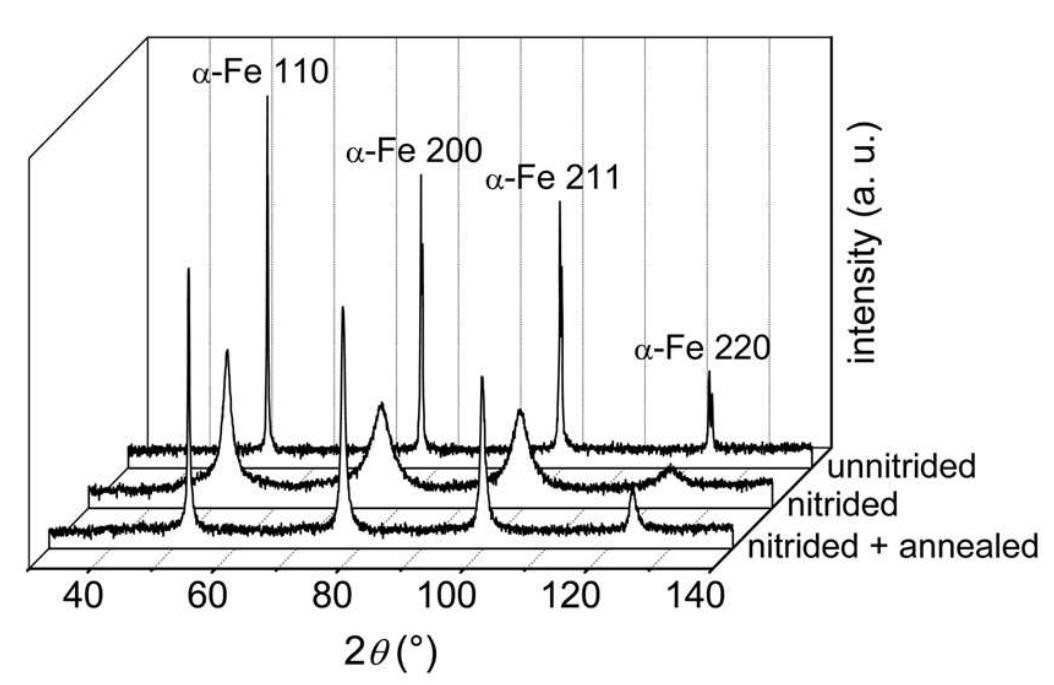

(b)

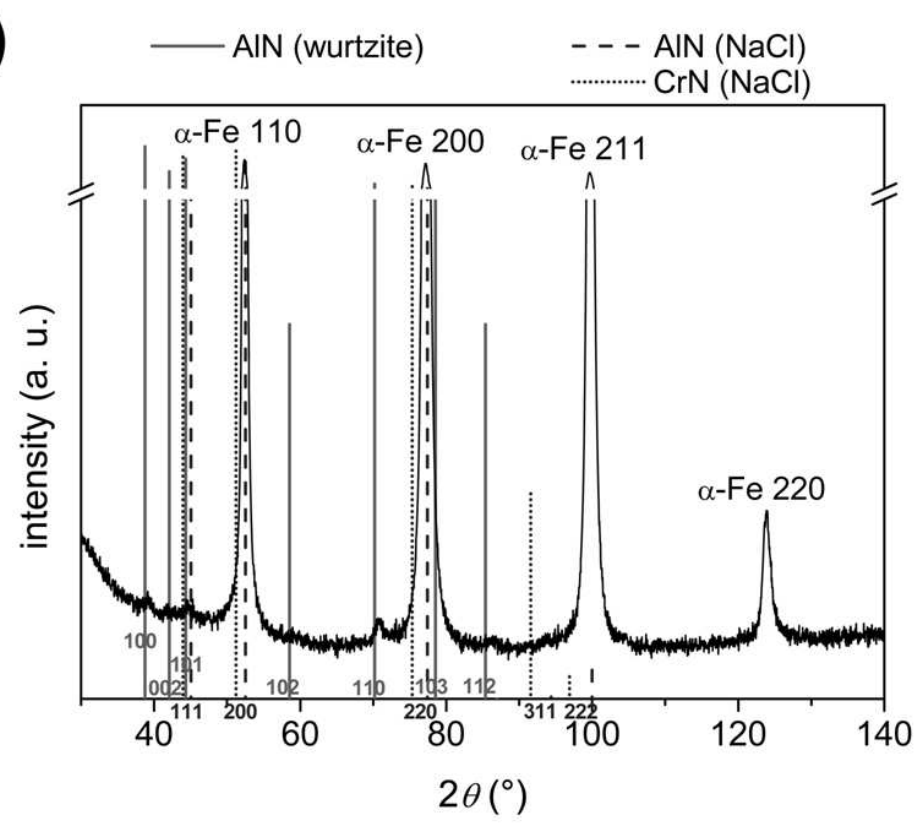

Fig. 3: (a)X ray diffractograms taken from the specimen surface before nitriding, after nitriding and after nitriding and annealing (counting time 10s/step). After nitriding a very pronounced peak broadening occurs, which becomes reduced upon subsequent annealing. (b)X ray diffractogram of the specimen surface after nitriding and annealing recorded applying longer counting times (100s/step) than in Fig. 3a in order to identify the intensity humps at the low-angle side of the $\alpha$ Fe110 reflection. Small peaks from the hexagonal AIN wurtzite structure can be observed. Presence or absence of peaks from the cubic-rock salt structure type AIN and CrN cannot be confirmed, because they generally are subject to strong overlapping with ferrite-matrix reflections. $160 \times 215 \mathrm{~mm}(150 \times 150 \mathrm{DPI})$ 
Fig. 4: BF image of a jet-electropolished TEM sample from the nitrided and annealed specimen near the surface, together with corresponding SADPs (electron-beam axis near [001] $\alpha_{\text {-Fe }}$ and EDX spectra of the ferrite matrix and precipitate (round particle).

\section{$160 \times 83 \mathrm{~mm}(150 \times 150 \mathrm{DPI})$}



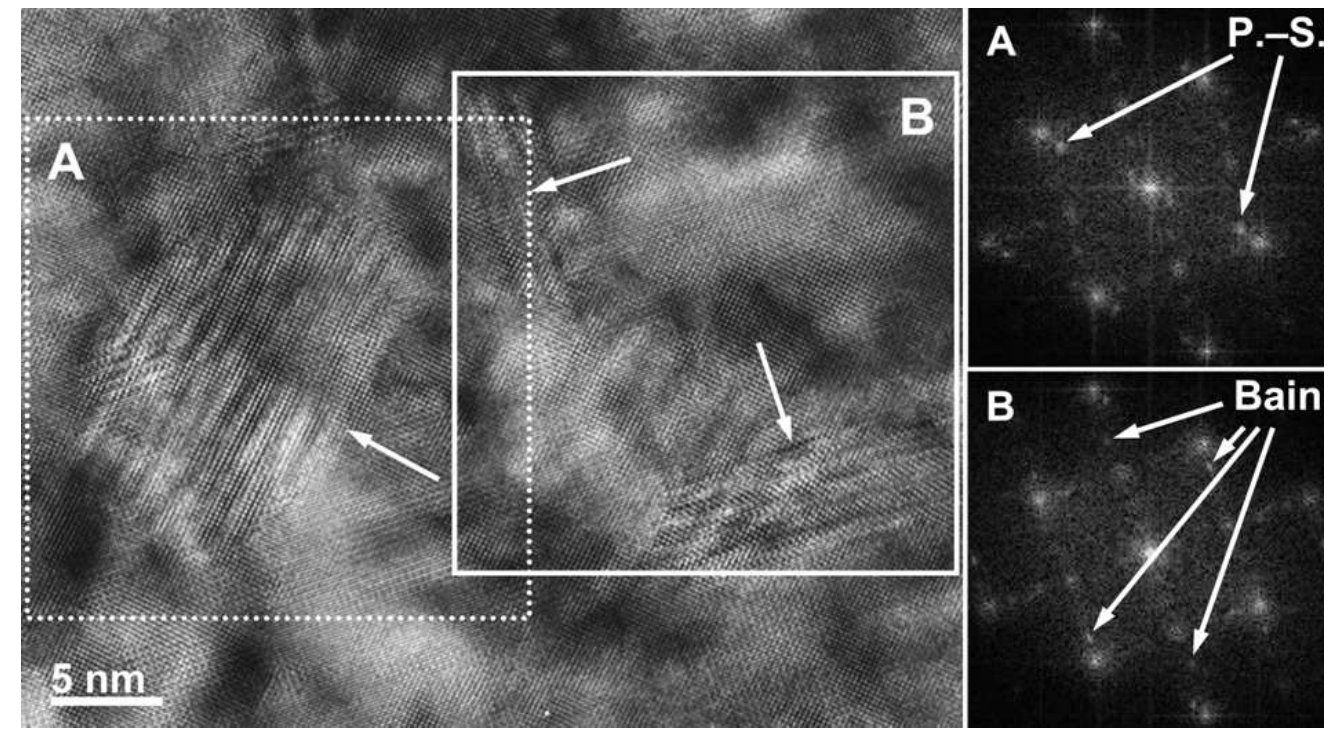

Fig. 5: HRTEM image of an ion-milled TEM sample from the nitrided and annealed specimen near the surface (electron-beam axis [001] $\boldsymbol{\alpha}_{-\mathrm{Fe}}$ ). The FFT patterns generated from an area with the roundish precipitate in the dotted square $A$ and from an area with platelet-like precipitates in the solid square $B$ are shown at the right. The roundish particle in A exhibits a Pitsch $\square$ Schrader OR with the ferrite matrix, whereas the more platelet-like particles in B satisfy the Bain OR with the ferrite matrix (cf. Fig. 1). $160 \times 88 \mathrm{~mm}(150 \times 150 \mathrm{DPI})$ 

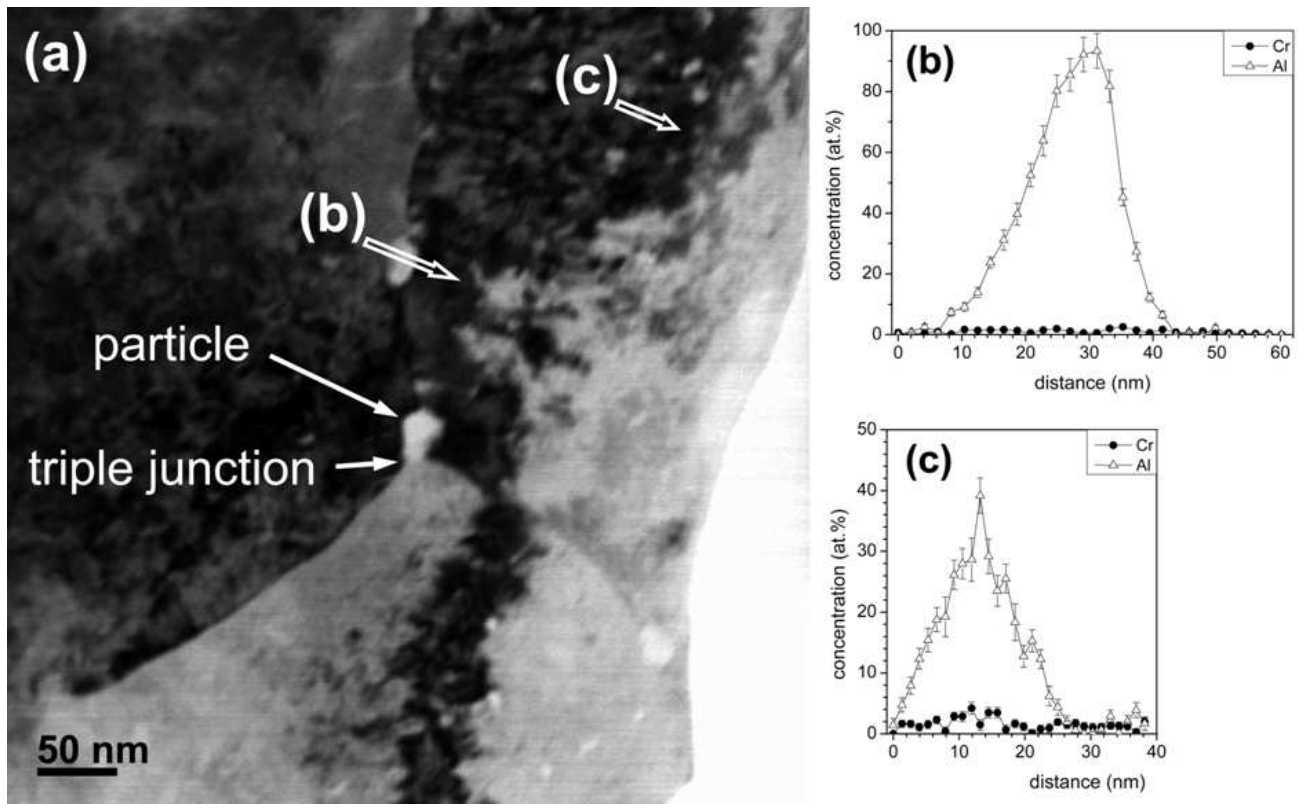

Fig. 6: (a)STEM BF image of three adjacent grains with triple junction in an ion-milled sample from the nitrided and annealed specimen near the surface and the results of STEM line-scans along paths (b) and (c) (see arrows). $160 \times 98 \mathrm{~mm}(150 \times 150 \mathrm{DPI})$ 


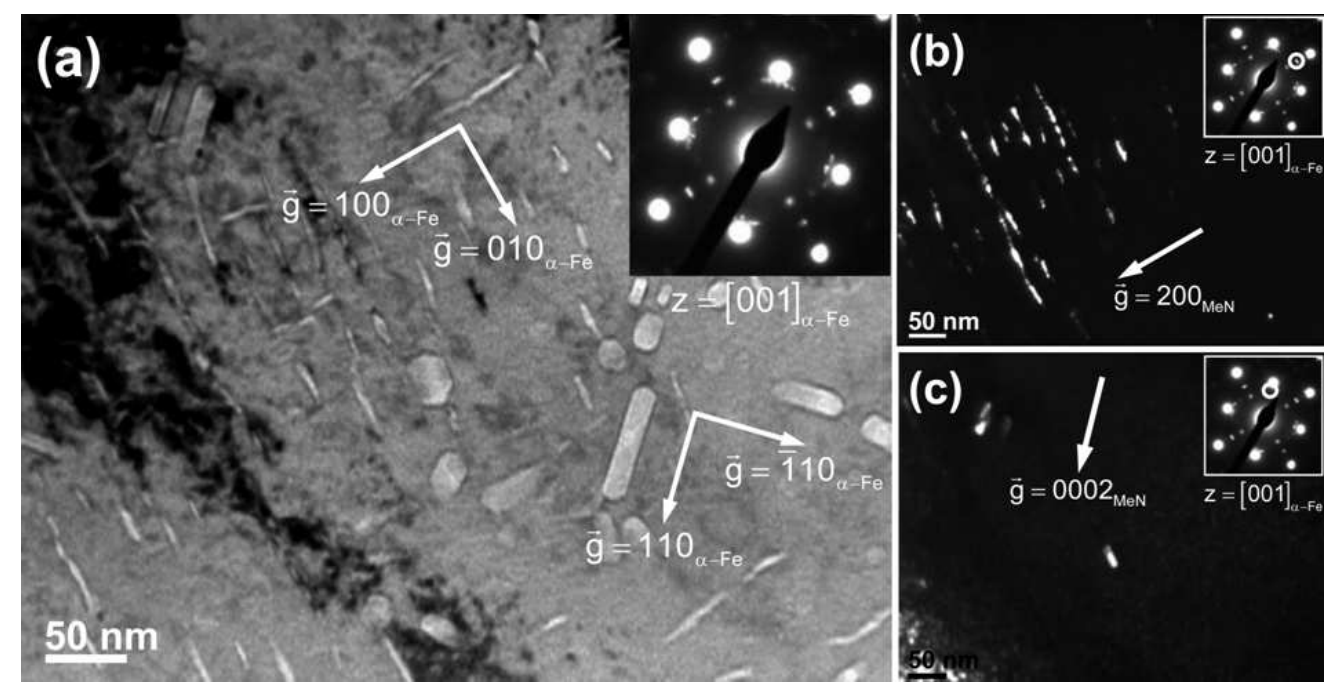

Fig. 7: (a)BF image and corresponding SADP of an ion-milled TEM sample from a nitrided and annealed specimen taken at a depth of about $215 \mu \mathrm{m}$ (electron-beam axis [001] $\boldsymbol{\alpha}_{-\mathrm{Fe}}$ ). (b)DF image obtained from a spot of rock-salt structure type precipitates having a Bain OR with the ferrite matrix. (c) DF image obtained from a or (cannot be distinguished; cf. Fig. 1) spot of the wurtzite structure type precipitates exhibiting a Pitsch $\square$ Schrader OR with the ferrite matrix (for analysing the SADP, see Fig. 1). $160 \times 81 \mathrm{~mm}(150 \times 150 \mathrm{DPI})$ 

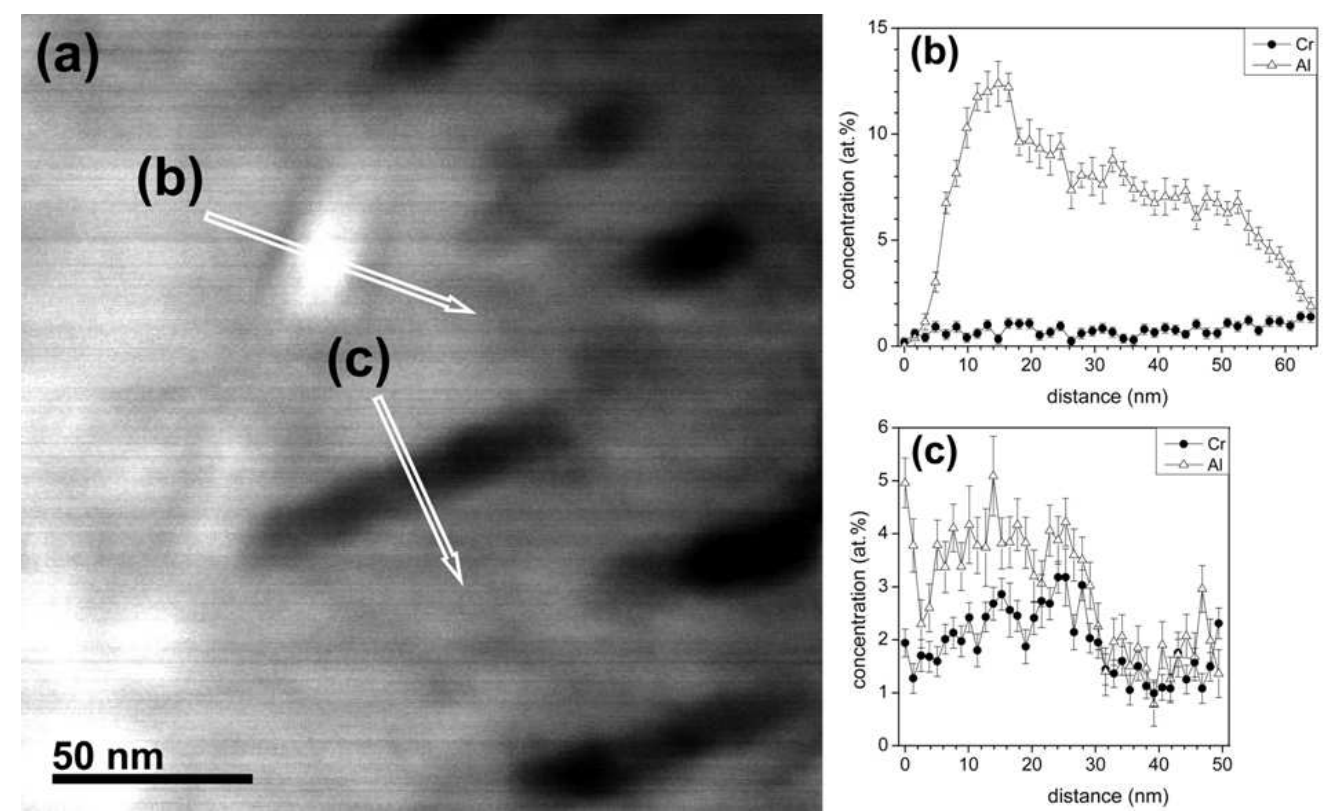

Fig. 8: (a)STEM BF image of an ion-milled TEM sample from a nitrided and annealed specimen taken at a depth of about $215 \mu \mathrm{m}$ showing two precipitates with different contrast. The image quality is poor because of the ferromagnetism of the material. (b)Results of the STEM line-scan of the bright precipitate in Fig. 8a (see arrow). (c)Results of the STEM line-scan of the dark precipitate in Fig. $8 a$ (see arrow).

$160 \times 98 \mathrm{~mm}(150 \times 150 \mathrm{DPI})$ 


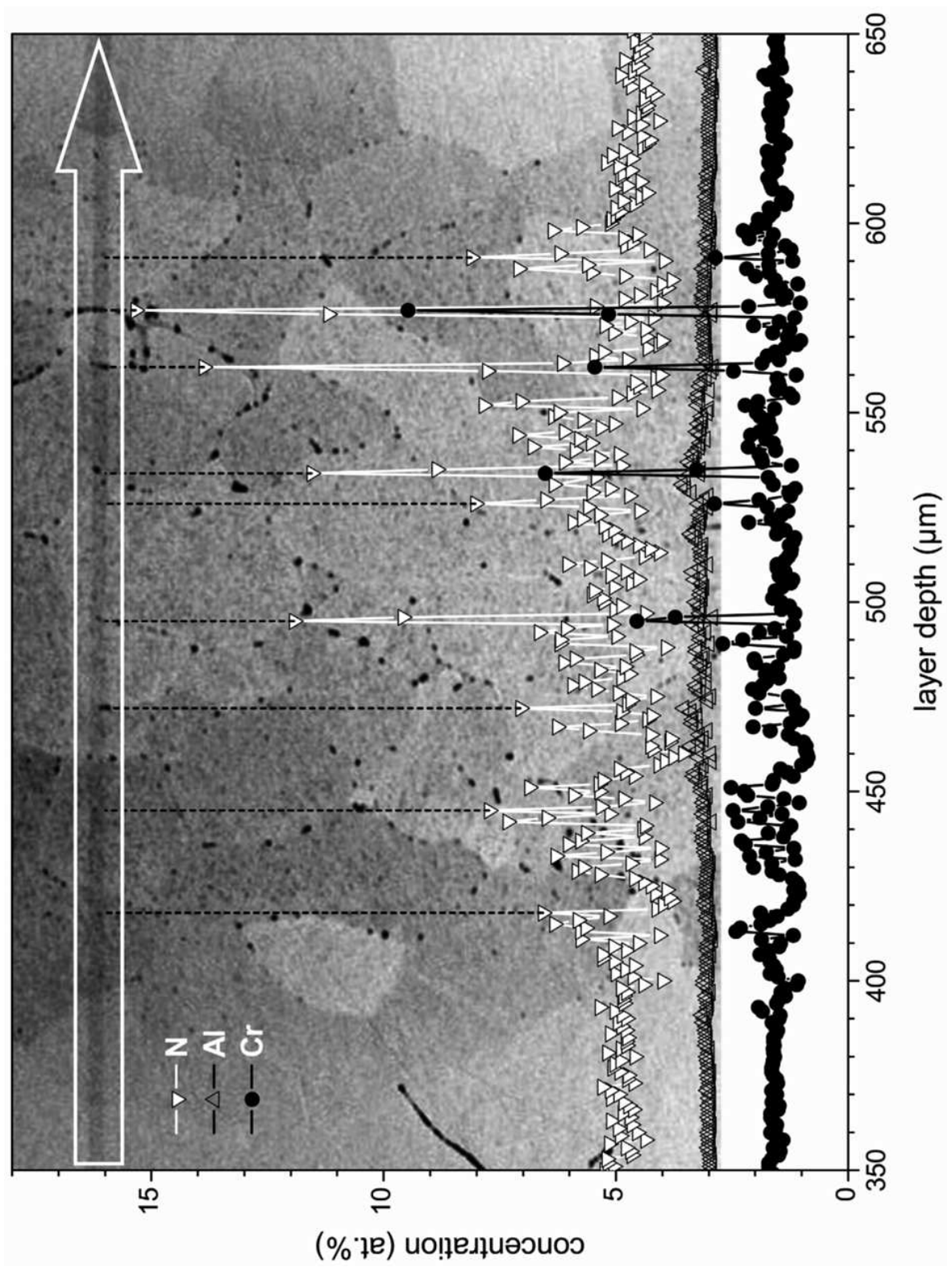

Fig. 9: EPMA concentration depth profile from the region around the specimen centre (initially the unnitrided core) after nitriding and subsequent annealing, together with the corresponding SEM micrograph. The white arrow indicates the course of the line-scan. The dashed vertical black lines denote points where the electron beam hit black particles mostly at matrix grain boundaries, which exhibit a local concentration increase of $\mathrm{N}$ and $\mathrm{Cr}$. $160 \times 213 \mathrm{~mm}(150 \times 150 \mathrm{DPI})$ 


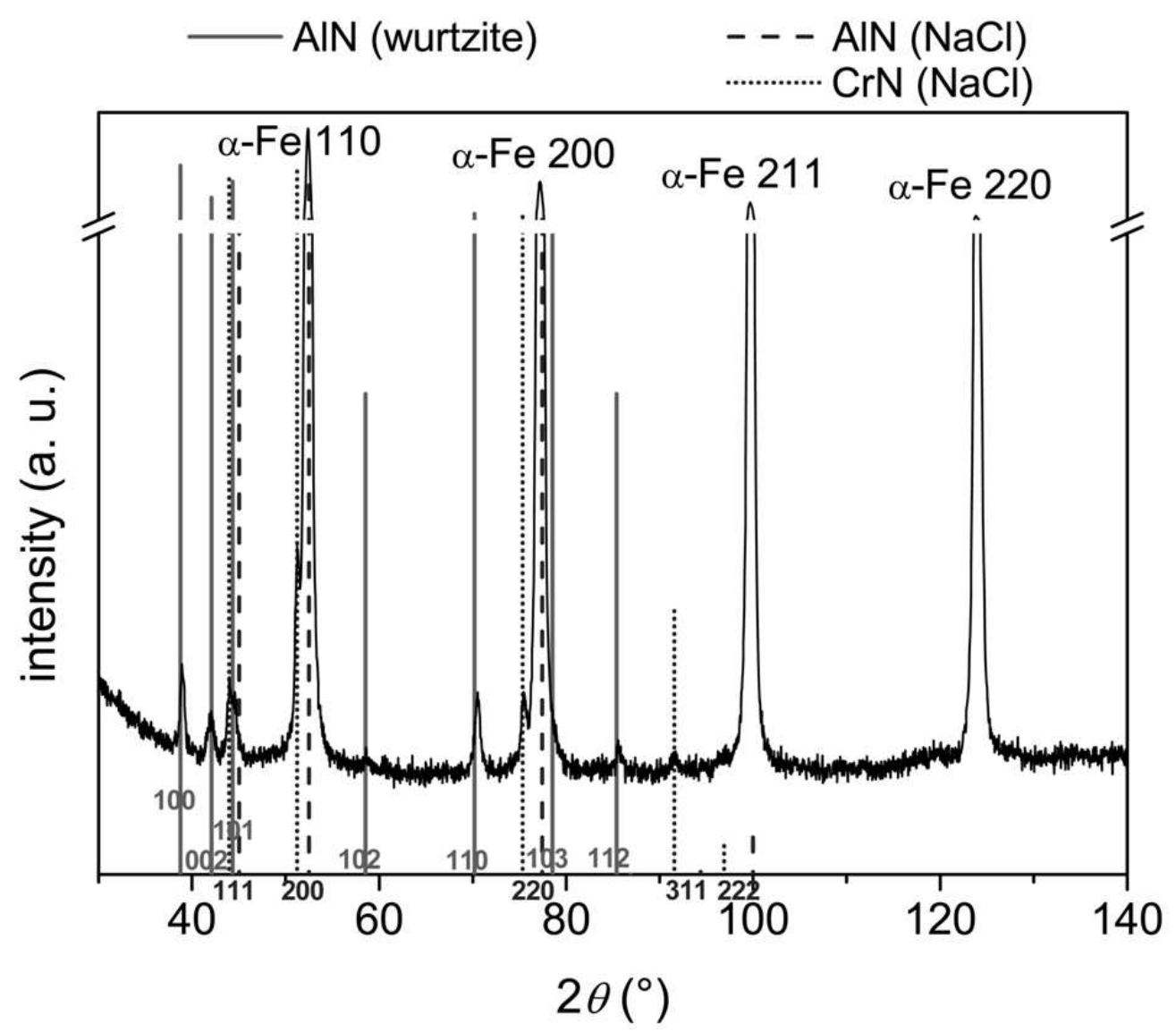

Fig. 10: $X$ ray diffractogram of the specimen centre (formerly unnitrided core, i.e. at about 500 $\mu m$ depth) for phase analysis after nitriding and annealing (counting time 120s/step). $160 \times 140 \mathrm{~mm}(150 \times 150 \mathrm{DPI})$ 


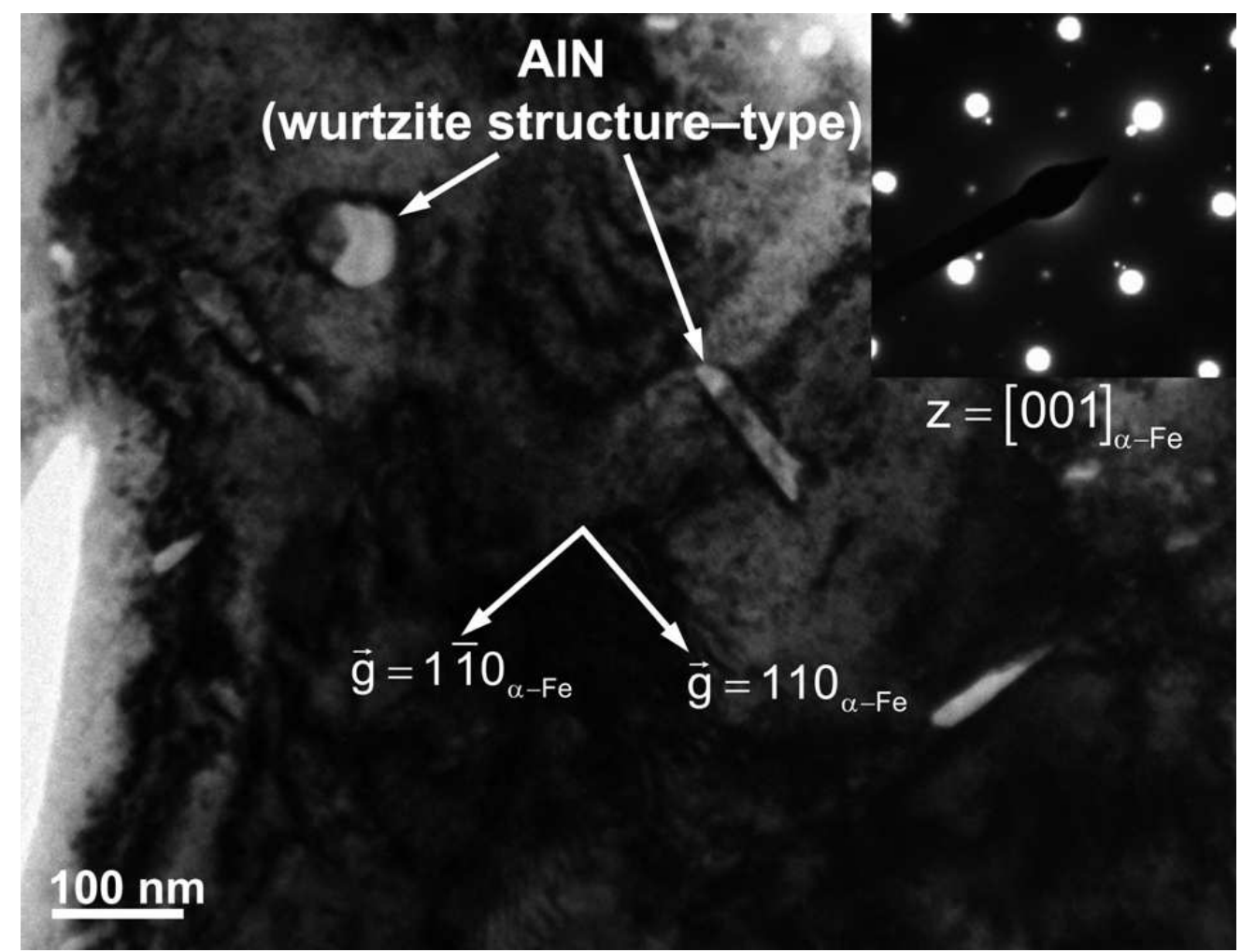

Fig. 11: BF image and corresponding SADP of an ion-milled TEM sample from a nitrided and annealed specimen taken at the specimen-centre area (initially the unnitrided core) showing coarse, wurtzite structure type precipitates, exhibiting a Pitsch $\square$ Schrader OR with the ferrite matrix (see SADP (inset; electron-beam axis [001] $\boldsymbol{\alpha}_{-\mathrm{Fe}}$ ) and cf. Fig. 1). $160 \times 123 \mathrm{~mm}(150 \times 150 \mathrm{DPI})$ 

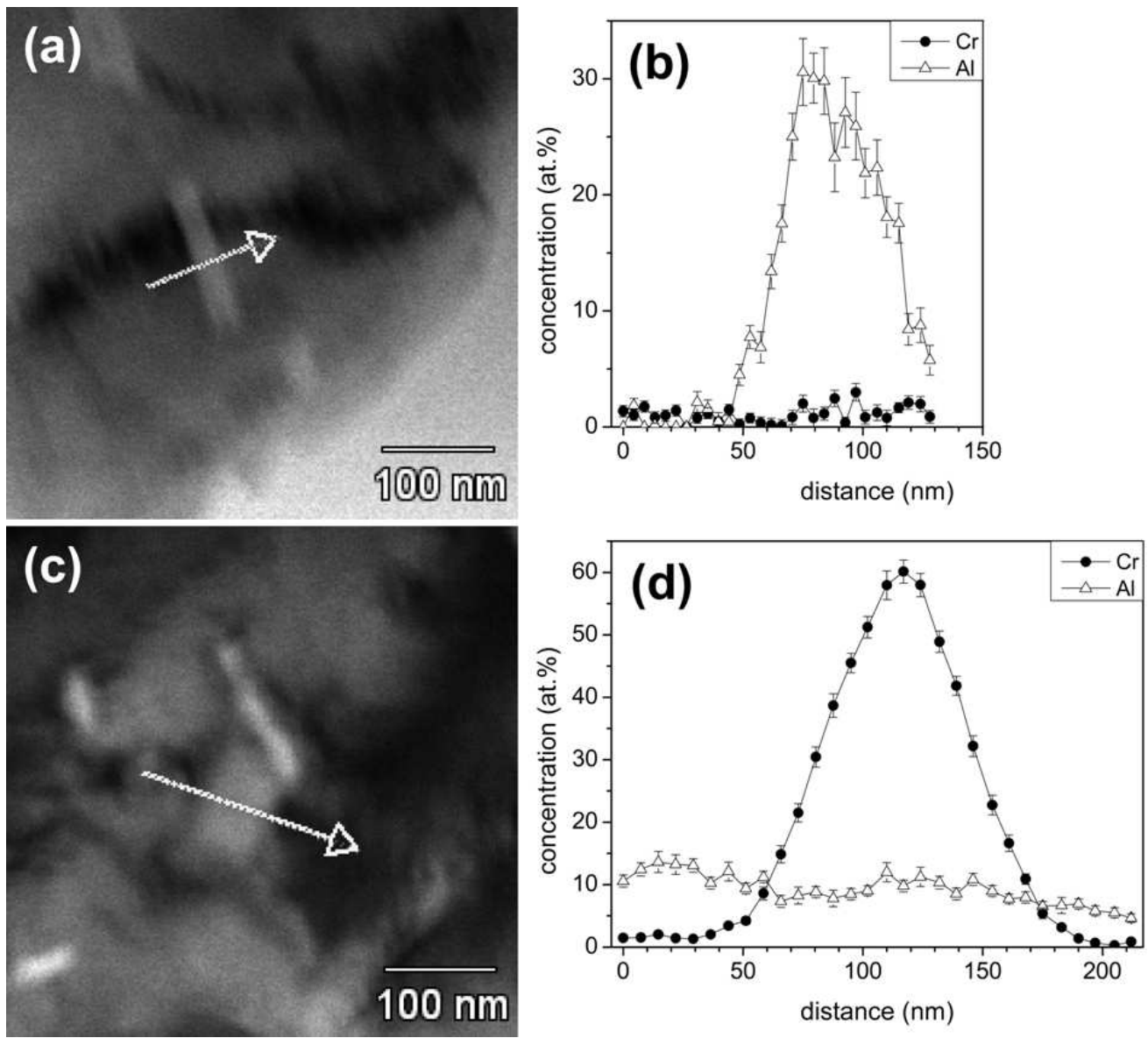

Fig. 12: (a)and (c) STEM BF images of an ion-milled TEM sample from a nitrided and annealed specimen taken at the specimen-centre area (initially the unnitrided core). (b)and(d)Results of the corresponding STEM line-scans (EDX; see arrows in Figs.12a and c). Figs.12a and b: only Al is detectable in the bright precipitate. Figs.12c and $\mathrm{d}$ : only $\mathrm{Cr}$ is detectable in the hardly visible precipitate. $160 \times 144 \mathrm{~mm}(150 \times 150 \mathrm{DPI})$ 


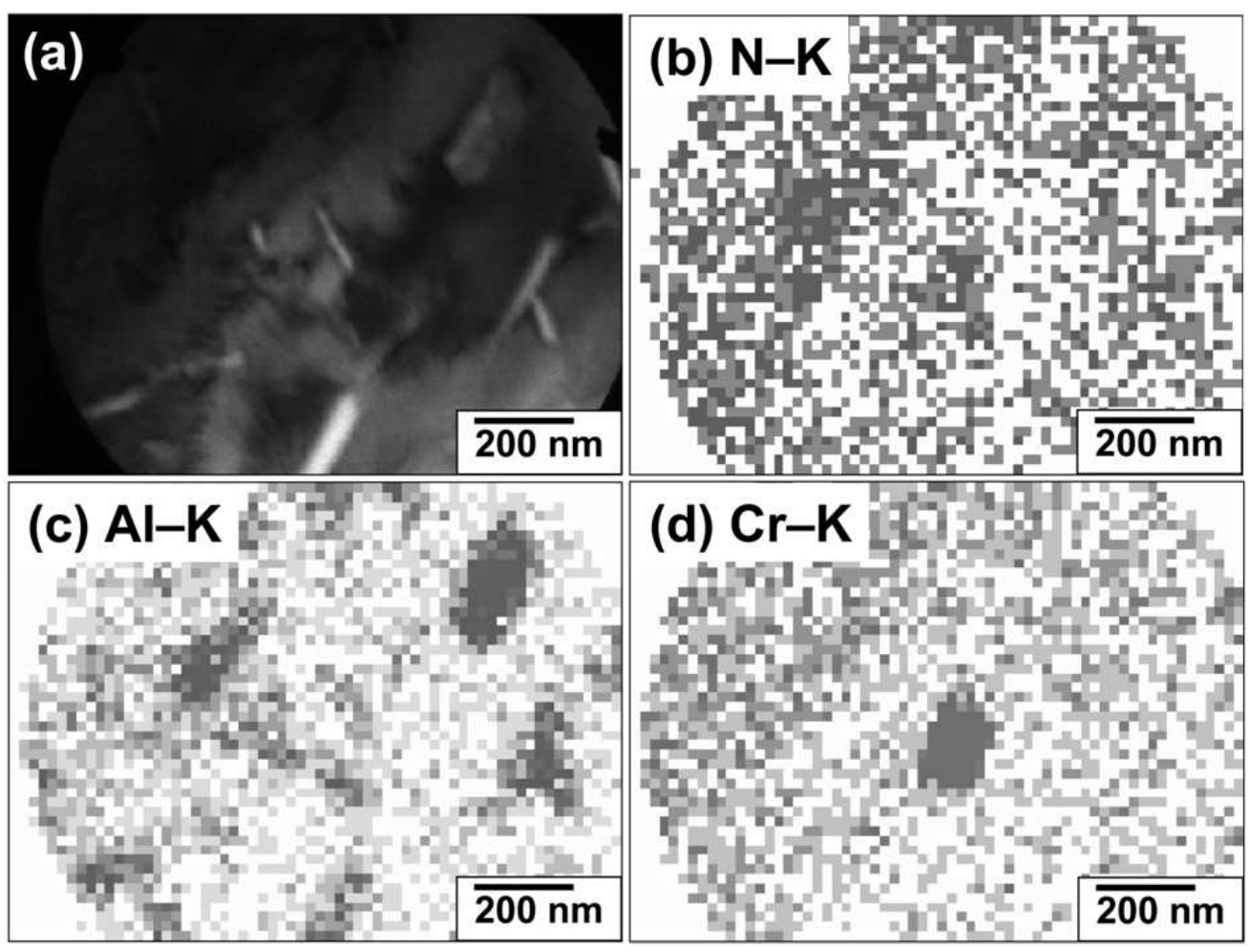

Fig. 13: (a)STEM BF image of an ion-milled sample from a nitrided and annealed specimen taken at the specimen-centre area (the formerly unnitrided core) and the results of element mapping for intensities of N口K, AI $\square \mathrm{K}$ and $\mathrm{Cr} \square \mathrm{K}$ : (b), (c) and (d) respectively. The bright precipitates can clearly be interpreted as AIN, whereas the CrN precipitate is hardly visible in the BF image. $160 \times 119 \mathrm{~mm}(150 \times 150 \mathrm{DPI})$ 